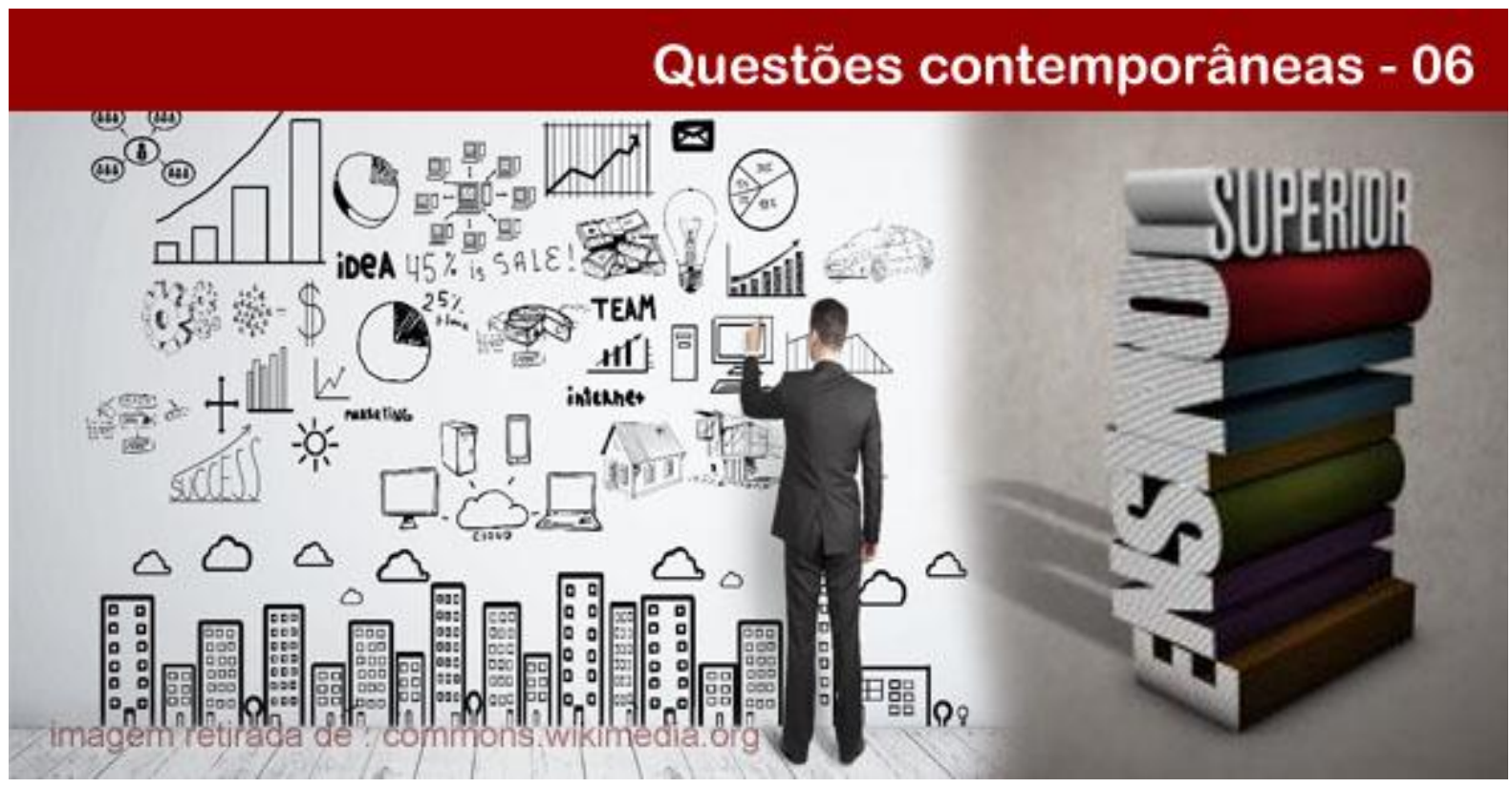

\title{
UMA PROPOSTA DE ANÁLISE DO PLANEJAMENTO ESTRATÉGICO EM INSTITUIÇÕES FEDERAIS DE ENSINO SUPERIOR
}

\section{José Leandro Candido}

Mestre em Administração Pública pela Universidade Federal de Campina Grande (UFCG). Administrador no IFPE. E-mail: leocandido89@gmail.com.

\section{Maria de Fátima Nóbrega Barbosa}

Doutora em Recursos Naturais pela Universidade Federal de Campina Grande (UFCG). Professora da graduação e pós-graduação da UFCG. E-mail: mfnobregabarbosa@gmail.com.

Resumo: O Planejamento Estratégico (PE) já é utilizado por instituições públicas como um processo de elaboração de estratégia há algum tempo. Nas Instituições de Ensino Superior (IES), o Plano de Desenvolvimento Institucional (PDI) tem sido adotado como instrumento de PE, porém, ainda enfrenta barreiras para sua institucionalização como instrumento de gestão, representando, em alguns casos, o cumprimento de uma formalidade institucional. Nesse contexto, o presente artigo concentra-se em apresentar uma proposta de análise do PE no âmbito das Instituições Federais de Ensino Superior (IFES), a partir de elementos críticos para sua integração com as ações realizadas. Para a compreensão do fenômeno no âmbito das IFES, recorreu-se à pesquisa bibliográfica como ferramenta útil para explorar o conhecimento científico existente acerca do tema. Contando com o auxílio da análise de conteúdo, foi possível apontar a existência de alguns elementos em comum, reconhecidos em diversos estudos de caso como relevantes no processo de elaboração e implementação do PE em IFES.

Palavras-chave: Planejamento Estratégico. Plano de Desenvolvimento Institucional. Instrumento de Gestão. Elementos Críticos.

\section{A PROPOSAL FOR ANALYSIS OF STRATEGIC PLANNING IN FEDERAL HIGHER EDUCATION INSTITUTIONS}

Abstract: Strategic Planning has already been used by public institutions as a strategy development process for some time. In Higher Education Institutions, the Institutional Development Plan has been adopted as a tool for strategic planning, but still faces barriers to its institutionalization as a management tool, representing, in some cases, compliance with a formality Institution. In this context, the present article focuses on presenting a proposal for the analysis of strategic planning within the Federal Higher Education Institutions based on critical elements for its integration with the actions carried out. For the understanding of the phenomenon in the scope of

\section{POLÊM!CA $\mid$ LABORË (3)}

Polêmica - Revista Eletrônica da Uerj - Rua São Francisco Xavier, 524, $1^{\circ}$ andar bloco D, sl.1001 • Tels.: +55 21 2334-4088/4087 • http://www.e-publicacoes.uerj.br/index.php/polemica/index http://www.labore.uerj.br • laboreuerj@yahoo.com.br 
the Federal Higher Education Institutions, bibliographical research was used as a useful tool to explore existing scientific knowledge about the subject. With the help of content analysis, it was possible to point out the existence of some elements in common, recognized in several case studies as relevant in the process of elaboration and implementation of strategic planning in Federal Higher Education Institutions.

Keywords: Strategic Planning. Institutional Development Plan. Management Instrument. Critical Elements.

\section{Introdução}

O termo "planejamento" é utilizado intuitivamente por pessoas há, praticamente, todo instante. "A forma mais simples de se definir planejamento é dizer que se deve pensar antes de agir" (PALUDO, PROCOPIUCK, 2014, p. 14, grifo do autor). Todavia, nem sempre essa forma intuitiva de planejar pode ser aplicada, em virtude de o ato de planejar envolver tanto situações simples quanto complexas.

Nas organizações, por exemplo, planejar não é tão simples assim, pois, geralmente, envolve um grande número de interessados que precisam ser compreendidos, contemplados e envolvidos para articular diversos recursos da mesma organização em torno de um objetivo comum. Para Oliveira (2014), o planejamento é um processo desenvolvido para o alcance de uma situação futura desejada, de um modo mais eficiente, eficaz e efetivo, com a melhor concentração de recursos pela empresa.

Em um ambiente de mutações constantes e com alto grau de interação entre os fatores internos da organização e fatores externos do ambiente, o Planejamento Estratégico (PE) tem ganhado destaque em relação ao planejamento tradicional. Ele busca uma interação empresa/ambiente que proporciona o entendimento e posicionamento proativo da empresa, com ênfase na identificação de soluções dos problemas relacionados com os ambientes externo e interno das organizações, trazendo uma preocupação maior com as novas tendências, descontinuidades e surpresas (PEREIRA, 1998; FALQUETO, 2012; MÜLLER, 2003).

Esse instrumento foi, inicialmente, desenvolvido para empresas do setor privado e vem sendo adotado por instituições públicas. Todavia, cabe salientar que há necessidade de se fazer as respectivas adaptações às especificidades dessa realidade, pois não existe uma maneira universal de planejamento ou receitas prontas que dão certo em qualquer situação (PEREIRA, 1998; GIACOBBO, 1997; BRYSON, 1988; PALUDO, PROCOPIUCK, 2014). Quando se trata de Instituições de Ensino Superior (IES), as especificidades existentes são ampliadas pelas peculiaridades de suas características e cultura organizacional.

\section{POLÊM!CA $\mid$ LABORE}


Em grande parte das IES, o instrumento que tem se consolidado como Planejamento Estratégico é o Plano de Desenvolvimento Institucional (PDI) (MAGALHÃES, 2009; SANTOS et al, 2009; FALQUETO, 2012; COSTA, 2014). Apesar de ser desenvolvido de acordo com as regulamentações do Sistema Nacional de Avaliação da Educação Superior (SINAES), durante o presente trabalho, o PDI não é analisado como um simples documento que visa atender às normas vigentes, mas efetivamente como um instrumento de gestão cujos objetivos, estratégias, ações e planos de trabalho devem efetivamente atuar como guia das atitudes e ações da instituição.

Algumas IES já possuíam iniciativas próprias de planejamento antes da obrigatoriedade de elaboração do PDI, entretanto, a exigência legal de avaliação contínua nas instituições de ensino superior surgiu como uma força facilitadora da implantação do PE (FALQUETO, 2012; SILVEIRA et al., 2009).

Apesar da consolidação do PDI como Planejamento Estratégico, poucas universidades públicas brasileiras têm efetivamente utilizado o mesmo como instrumento de gestão e, em muitos casos, cumprem uma função meramente formal e burocrática, sem a participação concreta da comunidade acadêmica, sem condições de serem colocados em prática ou tornálos sistemáticos, com experiências episódicas e descontínuas, abrangendo um período específico da administração de um reitor (BAENA, 2012; SANTOS et al., 2009; ESTRADA, 2001; COSTA, 2014).

Por essa razão, demonstra-se tão relevante o tema abordado, uma vez que busca identificar quais elementos são críticos para que o processo de planejamento estratégico possa representar um instrumento sistemático de gestão no âmbito das Instituições Federais de Ensino Superior (IFES).

Assim, utilizando-se da pesquisa bibliográfica e análise de conteúdo, este artigo apresenta resultados parciais de pesquisa realizada durante conclusão do Mestrado Profissional em Administração Pública e tem por objetivo apresentar uma proposta de análise do Planejamento Estratégico no âmbito das IFES a partir de elementos críticos para sua integração com as ações realizadas.

\section{POLÊM!CA $\mid$ LABORE}




\section{Planejamento Estratégico em IFES}

Não são muitos os modelos de PE que podem fornecer um esquema aplicável a organizações de ensino superior (FALQUETO, 2012), entretanto, Rebelo et al. (2003), Estrada (2000, 2001), Falqueto (2012) e FORPLAD (1995) apresentam os seguintes modelos, considerados tradicionais e conhecidos, por serem concebidos, especialmente, para organizações públicas e para as sem fins lucrativos, e aparecerem com frequência na literatura sobre organizações universitárias, conforme quadro 1.

Quadro - 1: Modelos de Planejamento Estratégico

\begin{tabular}{|c|c|c|c|}
\hline Bryson (1995) & Arguin (1989) & Cunha (1995) & FORPLAD (1995) \\
\hline & & I - Cultura e Poder & \\
\hline & & $\begin{array}{l}\text { II - Sistema } \\
\text { Organizacional }\end{array}$ & \\
\hline 1. Acordo inicial & $\begin{array}{l}\text { 1. Filosofia e orientação da } \\
\text { Instituição }\end{array}$ & 1. Visão & 1. Definição da Missão \\
\hline 2. Atribuiçõos & 2. Análise do meio externo & 2. Valores & $\begin{array}{l}\text { 2. Análise do ambiente } \\
\text { externo }\end{array}$ \\
\hline 3. Missão e valores & 3. Análise do meio interno & 3. Missão & $\begin{array}{l}\text { 3. Análise do ambiente } \\
\text { interno }\end{array}$ \\
\hline 4. Avaliação do ambiente & $\begin{array}{l}\text { 4. Integração do meio } \\
\text { externo e do meio interno }\end{array}$ & 4. Grupos de relação & $\begin{array}{l}\text { 4. Elaboração das questões } \\
\text { estratégicas }\end{array}$ \\
\hline 5. Grupos estratégicos & & $\begin{array}{l}\text { 5. Oportunidades e } \\
\text { ameaças }\end{array}$ & $\begin{array}{l}\text { 5. Elaboração dos projetos } \\
\text { que contemplem as ações } \\
\text { estratégicas }\end{array}$ \\
\hline $\begin{array}{l}\text { 6. Formulação } \\
\text { estratégica }\end{array}$ & & 6. Pontos fortes e fracos & $\begin{array}{l}\text { 6. Elaboração dos planos } \\
\text { de ação }\end{array}$ \\
\hline $\begin{array}{l}\text { 7. Revisão e adoção do } \\
\text { plano }\end{array}$ & & 7. Questões estratégicas & $\begin{array}{l}\text { 7. Elaboração dos } \\
\text { mecanismos de } \\
\text { acompanhamento }\end{array}$ \\
\hline 8. Visão de sucesso & & 8. Estratégias & \\
\hline 9. Implementação & & 9. Ações estratégicas & \\
\hline $\begin{array}{l}\text { 10. Reavaliação do } \\
\text { processo }\end{array}$ & & & \\
\hline
\end{tabular}

Fonte: Os autores (2016), baseado em Rebelo et al (2003), Estrada (2000 e 2001), Falqueto (2012) e FORPLAD (1995).

Por meio da análise de estudos de caso (ESTRADA, 2001; MAGALHÃES, 2009; SANTOS et al., 2009; SILVEIRA et al., 2009; HARGER, 2011; BOLZAN et al., 2012; FALQUETO, 2012; PETRASSI et al., 2013; COSTA, 2014; VIDIGAL, CAMPOS, 2015), têm-se observado que os modelos acima apresentados não são necessariamente seguidos

\section{POLÊM!CA LABORE}

Polêmica - Revista Eletrônica da Uerj - Rua São Francisco Xavier, 524, $1^{\circ}$ andar bloco D, sl.1001 • Tels.: +55 21 2334-4088 / 4087 • http://www.e-publicacoes.uerj.br/index.php/polemica/index http://www.labore.uerj.br • laboreuerj@yahoo.com.br 
rigidamente durante a elaboração e implementação do PE em IFES. Todavia, o estabelecimento da missão, análise interna e externa e elaboração das estratégias e da forma que serão implementadas acentuam-se como premissas básicas do PE independentemente das divergências encontradas nos modelos (ESTRADA, 2000).

Apesar de não seguirem rigidamente os modelos tradicionais de desenvolvimento do PE, as IFES têm apresentado elementos comuns na sua elaboração e implementação. Esses elementos são apresentados como fundamentais ao processo de implementação do PE, sendo considerados elementos críticos para a integração das ações realizadas ao planejamento desenvolvido. A seguir, serão apresentados os procedimentos metodológicos adotados durante a presente pesquisa para identificar tais elementos.

\section{Procedimentos metodológicos}

O trabalho possui perfil de uma pesquisa qualitativa, pois não se preocupa com representatividade numérica, mas sim, com o aprofundamento da compreensão de um tipo de organização (SILVEIRA, CORDOVA, 2009). Quanto à sua natureza, caracteriza-se por buscar entender e resolver problemas específicos relacionados a aplicações concretas, classificando-se, portanto, como pesquisa aplicada.

Quanto aos objetivos, pretende-se descrever os fatos e fenômenos da realidade estudada, destacando-se, assim, o perfil de pesquisa exploratório-descritiva (MARCONI, LAKATOS, 2010).

Apesar da pesquisa bibliográfica ser um procedimento adotado em regra para revisão de literatura com a finalidade de subsidiar os argumentos e fundamentos da pesquisa, no caso em tela, o estudo realça o perfil de pesquisa bibliográfica. Sua finalidade transpassa a simples revisão de literatura, tendo em vista que, dentre os trabalhos consultados, não se encontrou pesquisa que tenha como foco principal a identificação e delimitação dos elementos críticos para integração das ações ao planejamento estratégico em IFES.

Nesse sentido, utilizou-se a análise de conteúdo, com fundamento em orientações de Bardin (2011), para inferir, por meio de critérios sistemáticos e claramente definidos, quais elementos se destacam na literatura ao se tratar do planejamento estratégico em IFES, obedecendo aos parâmetros para coleta de dados apresentados a seguir.

\section{POLÊM!CA | LABORE}


Inicialmente, foram realizadas buscas no Portal de Periódico Capes, Google Acadêmico, SciELO, Plataforma Spell e Repositório UFSC, por trabalhos publicados durante o período de 2000-2015, contendo no título as palavras-chave "planejamento" e "universidade".

A busca retornou um total de 219 resultados válidos, entretanto, buscando a maximização das respostas encontradas, procedeu-se à seleção de resultados relevantes, adotando como critério a identificação de trabalhos que possuíssem como foco principal a análise do PE em IFES. A seleção foi realizada por meio da leitura do título, resumo e, quando estes não demonstraram-se suficientes para estabelecer se o trabalho atendia aos critérios de composição da amostra, as considerações finais do trabalho, culminando em 17 resultados relevantes, apresentados no Quadro 2.

Quadro - 2: Publicações relevantes para a pesquisa

\begin{tabular}{|c|c|c|}
\hline TÍTULO & AUTOR & ANO \\
\hline $\begin{array}{l}\text { Os rumos do Planejamento Estratégico na universidade pública: } \\
\text { um estudo de caso na Universidade Federal de Santa Maria }\end{array}$ & ESTRADA, Rolando Juan Soliz & 2000 \\
\hline $\begin{array}{l}\text { Uma experiência de Planejamento Estratégico em universidade: o } \\
\text { caso do Centro de Ciências Sociais Aplicadas da UFRN }\end{array}$ & $\begin{array}{l}\text { BORGES, Djalma Freire; } \\
\text { ARAÚJO, Maria Arlete Duarte de }\end{array}$ & 2001 \\
\hline $\begin{array}{l}\text { Sistema de Planejamento Institucional da Universidade de } \\
\text { Brasília: uma análise no plano anual de atividades }\end{array}$ & $\begin{array}{l}\text { FANTAUZZI, Orlandina de } \\
\text { Almeida }\end{array}$ & 2009 \\
\hline $\begin{array}{l}\text { Processo de Aprendizagem Organizacional durante a } \\
\text { Implementação do Planejamento Estratégico na Universidade } \\
\text { Federal de Alagoas }\end{array}$ & SANTOS, Jane Lucia Silva & 2009 \\
\hline $\begin{array}{l}\text { Uma experiência de Planejamento Estratégico no contexto da } \\
\text { Universidade Federal de Goiás }\end{array}$ & $\begin{array}{l}\text { SILVEIRA, Everton Wirbitzki da; } \\
\text { OLIVEIRA, Marcio medeiros; } \\
\text { SERAPHIN, José Carlos; } \\
\text { VIEIRA, Regina Beatriz } \\
\text { bevilacqua }\end{array}$ & 2009 \\
\hline $\begin{array}{l}\text { Processo de Planejamento Estratégico em universidade pública: o } \\
\text { caso da Universidade Federal do Pará }\end{array}$ & ATHANÁZIO, Madeleine Mônica & 2010 \\
\hline $\begin{array}{l}\text { Planejamento Estratégico aplicado à gestão de universidade } \\
\text { pública }\end{array}$ & PICCHIAI, Djair & 2010 \\
\hline $\begin{array}{l}\text { Implantação do Planejamento Estratégico em universidades: o } \\
\text { caso da Universidade de Brasília }\end{array}$ & $\begin{array}{l}\text { FALQUETO, Júnia Maria } \\
\text { Zandonade }\end{array}$ & 2012 \\
\hline $\begin{array}{l}\text { Avaliação da Gestão do Planejamento da Universidade Federal de } \\
\text { Santa Catarina, Utilizando a Metodologia Multicritérios de Apoio } \\
\text { à Decisão }\end{array}$ & KOBUS, Mario & 2012 \\
\hline $\begin{array}{l}\text { As metas e os indicadores no processo de planejamento: o caso } \\
\text { de uma universidade pública }\end{array}$ & PICCHIAI, Djair & 2012 \\
\hline $\begin{array}{l}\text { O impacto do método e de fatores organizacionais no processo de } \\
\text { Planejamento Estratégico: estudo de caso em uma universidade } \\
\text { federal }\end{array}$ & $\begin{array}{l}\text { ALBANO, Claudio Sonaglio; } \\
\text { GARCIA, Fabiane Tubino }\end{array}$ & 2013 \\
\hline $\begin{array}{l}\text { Competências: análise a partir do Planejamento Estratégico de } \\
\text { um departamento de uma universidade federal }\end{array}$ & ANDREAZZA, Marcelo da Silva & 2013 \\
\hline $\begin{array}{l}\text { Estratégico e seus Instrumentos Aplicados em uma universidade } \\
\text { pública }\end{array}$ & PICCHIAI, Djair & 2013 \\
\hline Análise da Implementação do Planejamento Estratégico em & COSTA, Loreno Vaz & 2014 \\
\hline
\end{tabular}

\section{POLÊM!CA | LABORẸ}

Polêmica - Revista Eletrônica da Uerj - Rua São Francisco Xavier, 524, $1^{\circ}$ andar

bloco D, sl.1001 • Tels.: +55 21 2334-4088/4087 • http://www.e-publicacoes.uerj.br/index.php/polemica/index http://www.labore.uerj.br • laboreuerj@yahoo.com.br 


\begin{tabular}{|l|l|l|}
\hline $\begin{array}{l}\text { universidades públicas federais: o caso da Universidade Federal } \\
\text { do PAMPA }\end{array}$ & \\
\hline $\begin{array}{l}\text { O Planejamento Estratégico como instrumento de mudança na } \\
\text { Universidade Federal de Pernambuco }\end{array}$ & $\begin{array}{l}\text { CARDOSO, Carla Ionara Xavier } \\
\text { da Silveira; } \\
\text { SANTOS, Jorge Luis dos; } \\
\text { ROSA, Patricia da Silva Santa; } \\
\text { ESTRELLA, Wilza Maria } \\
\text { Aparecida de Melo }\end{array}$ & 2015 \\
\hline $\begin{array}{l}\text { Planejamento em IFES: a experiência da UFRB - Universidade } \\
\text { Federal do Recôncavo da Bahia }\end{array}$ & $\begin{array}{l}\text { SANTOS, Geovane Santana dos; } \\
\text { LIMA, Adyla Ramos da Silva; } \\
\text { SCHEFFLER, Marco Polo }\end{array}$ & 2015 \\
\hline $\begin{array}{l}\text { Do Planejamento Estratégico à Prática de Gestão na universidade } \\
\text { pública: um estudo na UFG }\end{array}$ & $\begin{array}{l}\text { VIDIGAL, Frederico; } \\
\text { CAMPOS, Lelia Wanderley de }\end{array}$ & 2015 \\
\hline
\end{tabular}

Fonte: Os autores (2016).

Para tratamento dos dados, utilizou-se, predominantemente, uma abordagem qualitativa que contou com o auxílio da técnica de análise de conteúdo, muito utilizada em estudos qualitativos no campo da administração (SILVA et al., 2013). Segundo Bardin (2011, p. 48), trata-se de:

Um conjunto de técnicas de análise das comunicações visando obter, por procedimentos sistemáticos e objetivos de descrição do conteúdo das mensagens, indicadores (quantitativos ou não) que permitam a inferência de conhecimentos relativos às condições de produção/recepção (variáveis inferidas) dessas mensagens.

A técnica conta com etapas compostas por: pré-análise, na qual é realizado o primeiro contato com os documentos que serão submetidos à análise, a escolha deles, a formulação das hipóteses e objetivos, a elaboração dos indicadores que orientarão a interpretação e a preparação formal do material; exploração do material, por meio da codificação e categorização do material analisado; e tratamento dos resultados - inferência e interpretação por meio do qual, calcado nos resultados brutos, o pesquisador procura torná-los significativos e válidos (BARDIN, 2011; CAMARA, 2013).

Para definição das categorias de análise, realizou-se a leitura prévia das dezessete publicações resultantes da busca no Portal de Periódico Capes, Google acadêmico, SciELO, Plataforma Spell e Repositório UFSC. Com isso, foi possível identificar preliminarmente quais elementos são mais referenciados pelos autores por influenciar no processo de Planejamento Estratégico em IFES.

Conforme orientado por Bardin (2011), procedeu-se à leitura mais detalhada dos dezessete artigos resultantes da busca, classificando os parágrafos por meio da análise temática, de acordo com as categorias adotadas e atribuindo um valor específico, por meio de

\section{POLÊM!CA $\mid$ LABORE}


critérios claramente definidos. Assim, para determinação de quais seriam os elementos mais relevantes foram adotados como critérios: a) A quantidade de publicações que abordam o elemento; b) Ênfase dada ao elemento no trabalho; c) Ênfase dada ao elemento no parágrafo, conforme pode ser observado na Tabela 01 .

Tabela - 1: Critérios para categorização dos temas/elementos

\begin{tabular}{clc}
\hline CÓD. & \multicolumn{1}{c}{ CRITÉRIO } & VALOR \\
\hline A & Quantidade de publicações que abordam o elemento & 1 \\
B & Ênfase dada ao elemento no trabalho & 1 \\
& - Mencionado apenas como mais um dos elementos que influenciam & \\
& no desenvolvimento do PE; & 2 \\
& - Mencionado com um elemento relevante para o PE; & 3 \\
& - Uma pequena parte do trabalho é dedicada ao elemento; & 4 \\
& - Uma parte significativa do trabalho é dedicada ao elemento; & 5 \\
& - O elemento é um dos temas mais abordados pelo autor; & 6 \\
& - O elemento faz parte do tema principal do trabalho; & 1,0 \\
& Ênfase dada ao elemento no parágrafo & 1,2 \\
& - Elemento a ser considerado pelo PE; & 1,4 \\
& - Elemento necessário ao PE; & 1,6 \\
& - Elemento que afeta indiretamente o PE; & 1,8 \\
& - Elemento que afeta diretamente o PE; & \\
& - Parte fundamental do PE; & \\
\end{tabular}

Fonte: Os autores (2016).

O tamanho do trabalho e o número de referências dedicadas a um tema/elemento em um artigo científico, quando comparado a uma dissertação ou tese, por exemplo, pode gerar distorções em relação ao resultado. Por isso foi adotado como mecanismo de segurança a padronização do valor de cada elemento no texto de tal maneira, que a soma de todos os elementos do texto fosse igual a 100. Dessa maneira, qualquer trabalho analisado teve pontuação máxima de 100 pontos, e o valor atribuído a cada elemento representa a relevância que o seu autor atribui ao mesmo em relação aos demais naquele trabalho específico, conforme poderá ser observado na Tabela 02, no próximo tópico.

O grau de importância conferido a cada tema/elemento em uma publicação específica foi definido pela soma do valor atribuído a cada parágrafo no qual foi abordado (C), multiplicado pelo valor atribuído à ênfase dada ao elemento no trabalho (B). Por fim, o valor proporcional atribuído ao tema/elemento, em uma publicação específica, foi somado ao valor atribuído nas demais publicações e multiplicado pelo número de trabalhos no qual o elemento é abordado (A).

Por meio dos critérios propostos, foi possível desenvolver uma forma objetiva de análise da importância dada a cada elemento nas dezessete publicações selecionadas, uma vez

\section{POLÊM!CA $\mid$ LABORE}

Polêmica - Revista Eletrônica da Uerj - Rua São Francisco Xavier, 524, $1^{\circ}$ andar

bloco D, sl.1001 • Tels.: +55 21 2334-4088/4087 • http://www.e-publicacoes.uerj.br/index.php/polemica/index http://www.labore.uerj.br • laboreuerj@yahoo.com.br 
que foram considerados: cada parágrafo, no qual o elemento foi abordado, e a ênfase dada ao elemento no parágrafo. Na sequência, aplicou-se as seguintes fórmulas, respectivamente:

$\left.1^{\circ}\right) \mathrm{Y}=\mathrm{C}_{1}+\mathrm{C}_{2}+\mathrm{C}_{3}+\ldots+\mathrm{C}_{\mathrm{n}}$

$\left.2^{\circ}\right) \mathrm{Z}=\mathrm{Y} * \mathrm{~B}$;

$\left.3^{\circ}\right) \mathrm{T}=\mathrm{Z}_{1}+\mathrm{Z}_{2}+\mathrm{Z}_{3}+\ldots+\mathrm{Z}_{17}$

$\left.4^{\circ}\right) \mathrm{X}=\mathrm{T} * \mathrm{~A}$;

Onde:

$\mathrm{C}_{\mathrm{n}}$ - Pontuação da ênfase dada ao elemento no parágrafo 'n';

$B_{n}$ - Pontuação da ênfase dada ao elemento no trabalho 'n';

A - Quantidade de publicações que abordam o elemento;

$\mathrm{Y}_{\mathrm{n}}$ - Soma da pontuação do elemento nos parágrafos do trabalho 'n'.

$\mathrm{Z}_{\mathrm{n}}$ - Pontuação total do elemento no trabalho 'n';

T - Pontuação do elemento 'n' em todos os trabalhos;

$\mathrm{X}$ - Pontuação TOTAL do elemento;

Para não distorcer os resultados, cada parágrafo apenas foi considerado quando tratou do tema/elemento em relação ao Planejamento Estratégico, e não do tema isoladamente. Por exemplo, quando o autor abordava a 'natureza da instituição' e sua influência no processo de $\mathrm{PE}$, os parágrafos foram contabilizados. Entretanto, quando o autor passou a deter-se em analisar as especificidades da natureza da universidade em si, o parágrafo não foi contabilizado.

Por outro lado, a não contabilização dos parágrafos nos quais o autor se detinha ao tema sem correlacioná-lo com o Planejamento Estratégico foi compensada ao considerar a ênfase dada ao elemento no trabalho (B), uma vez que se entendeu que, quando o autor deteve-se a explicar pormenores do elemento, é porque o considerou importante em relação ao assunto do trabalho.

Dessa forma, o valor atribuído ao tema/elemento em cada trabalho foi somado aos demais e multiplicado pelo número de trabalhos que abordaram o tema (A). Esse critério objetivou dar maior destaque aos elementos que foram considerados por mais autores, enfatizando seu claro reconhecimento na literatura.

\section{POLÊM!CA $\mid$ LABORE}




\section{Elementos de integração do Planejamento Estratégico}

A análise prévia das dezessete publicações selecionadas possibilitou uma percepção clara de elementos comuns apresentados por diversos autores como influenciadores do processo de elaboração e implementação do PE em IFES. Os itens mais mencionados foram, respectivamente:

- $\quad$ Sistema de Informação;

- Know-how para trabalhar com o PE;

- $\quad$ Acompanhamento e avaliação;

- $\quad$ Cultura organizacional;

- $\quad$ Participação no PE;

- $\quad$ Natureza da organização;

- $\quad$ Estrutura organizacional;

- Questões políticas;

- $\quad$ Presença da liderança;

- $\quad$ Adoção do PE como instrumento de gestão;

- Definição de parâmetros para medição dos resultados;

- $\quad$ Processos;

- $\quad$ Comunicação;

- Manutenção de equipe permanente voltada ao planejamento estratégico;

- $\quad$ Análise e alinhamento ambiental;

- $\quad$ Articulação entre PE e orçamento;

- Definição clara das atribuições;

Apesar de todos os elementos anteriormente mencionados serem destacados pela literatura como fortes influenciadores do processo de PE, alguns ganharam maior destaque que outros, por isso, com a finalidade de apontar os principais elementos críticos para a integração das ações ao PE, optou-se por identificar os dez principais elementos críticos nesse processo.

Para determiná-los, contou-se com a análise de conteúdo, por meio dos critérios claramente definidos, conforme aponta a Tabela 01. Todos os trabalhos foram lidos minuciosamente, classificando os parágrafos que abordaram qualquer um dos elementos

\section{POLÊM!CA $\mid$ LABORE}

Polêmica - Revista Eletrônica da Uerj - Rua São Francisco Xavier, 524, $1^{\circ}$ andar bloco D, sl.1001 • Tels.: +55 21 2334-4088/4087 • http://www.e-publicacoes.uerj.br/index.php/polemica/index http://www.labore.uerj.br • laboreuerj@yahoo.com.br 
mencionados e atribuindo um valor à ênfase dada a cada elemento no parágrafo, conforme código " $\mathrm{C}$ " da referida tabela. $\mathrm{O}$ resultado $(\mathrm{Y})$ foi multiplicado pela ênfase dada ao elemento no trabalho, conforme Código "B" e, por fim, o valor do elemento em cada texto (Z) foi somado (T), e multiplicado pelo número de trabalhos que abordaram o elemento em tela (A).

Para fins ilustrativos, é apresentado na Tabela 02 o resultado da metodologia quando aplicada no trabalho de Estrada (2000) em relação às categorias de análise (Cód. "B" e Cód. “C”).

Tabela - 2: Aplicação: pontuação e pontuação proporcional ${ }^{1}$

\begin{tabular}{|c|c|c|}
\hline TEMA/ELEMENTO & PONTUAÇÃO & $\begin{array}{l}\text { PONTUAÇÃO } \\
\text { PROPORCIONAL }\end{array}$ \\
\hline Adoção do PE como instrumento de gestão & 1,6 & 0,9489 \\
\hline Análise e alinhamento ambiental & - & - \\
\hline Participação no Planejamento Estratégico & 1,2 & 0,7117 \\
\hline Comunicação & - & - \\
\hline Definição clara das atribuições & - & - \\
\hline Cultura organizacional & 36,6 & 21,7082 \\
\hline Questões políticas & 25,6 & 15,1839 \\
\hline \multicolumn{3}{|l|}{ Natureza da organização } \\
\hline Estrutura organizacional & 26,8 & 15,8956 \\
\hline Know-how para trabalhar com o Planejamento Estratégico & 21,2 & 12,5741 \\
\hline Articulação entre Planejamento estratégico e Orçamento & 1,6 & 0,9489 \\
\hline Processos & - & - \\
\hline Sistema de informação & 6,8 & 4,0332 \\
\hline Presença da liderança & 21,6 & 12,8114 \\
\hline $\begin{array}{l}\text { Manutenção de equipe permanente voltada ao planejamento } \\
\text { estratégico }\end{array}$ & - & - \\
\hline Definição de parâmetros para medição dos resultados & 13,2 & 7,8291 \\
\hline Acompanhamento e Avaliação & 12,4 & 7,3546 \\
\hline TOTAL & 168,6 & 100 \\
\hline
\end{tabular}

Fonte: Os autores (2016).

É importante realçar que para o cálculo final dos valores atribuídos a cada elemento foram considerados os valores proporcionais atribuídos aos elementos, conforme anteriormente apresentado nos procedimentos metodológicos.

Após codificação e categorização dos dados, obteve-se a pontuação individual de cada elemento nos dezessete trabalhos analisados. Essas pontuações foram somadas e multiplicadas pela quantidade de publicações que abordavam cada elemento, culminando no ranking dos principais elementos críticos apontados na Tabela 03.

\footnotetext{
${ }^{1}$ A Tabela 2 trata-se de um exemplo da aplicação dos critérios de categorização no trabalho de Estrada (2000).
}

\section{POLÊM!CA $\mid$ LABORE}

Polêmica - Revista Eletrônica da Uerj - Rua São Francisco Xavier, 524, $1^{\circ}$ andar

bloco D, sl.1001 • Tels.: +55 21 2334-4088/4087 • http://www.e-publicacoes.uerj.br/index.php/polemica/index http://www.labore.uerj.br • laboreuerj@yahoo.com.br 
Tabela - 3: Pontuação dos elementos críticos

\begin{tabular}{clc}
\hline Classificação & \multicolumn{1}{c}{ Elemento Crítico } & Pontuação Total \\
\hline $1^{\circ}$ & Sistema de Informação & 3261 \\
$2^{\circ}$ & Know-how para trabalhar com o Planejamento Estratégico & 2241 \\
$3^{\circ}$ & Acompanhamento e Avaliação & 1964 \\
$4^{\circ}$ & Cultura organizacional & 1919 \\
$5^{\circ}$ & Participação no Planejamento Estratégico & 1480 \\
$6^{\circ}$ & Natureza da organização & 1030 \\
$7^{\circ}$ & Estrutura organizacional & 1025 \\
$8^{\circ}$ & Questões políticas & 1005 \\
$9^{\circ}$ & Presença da liderança & 997 \\
$10^{\circ}$ & Adoção do PE como instrumento de gestão & 803 \\
$11^{\circ}$ & Definição de parâmetros para medição dos resultados & 620 \\
$12^{\circ}$ & Processos & 456 \\
$13^{\circ}$ & Comunicação & 357 \\
$14^{\circ}$ & Manutenção de equipe permanente voltada ao Planejamento & 190 \\
$15^{\circ}$ & Estratégico & 169 \\
$16^{\circ}$ & Análise e alinhamento ambiental & 64 \\
$17^{\circ}$ & Articulação entre Planejamento estratégico e Orçamento & 28 \\
\hline
\end{tabular}

Fonte: Os autores (2016).

É possível observar, então, quais são os dez principais elementos considerados na literatura em relação à elaboração e implementação do PE em IFES. Dentre os casos analisados, observa-se a relevância da presença de Sistemas de Informação que possibilitem a sistematização das informações, gerenciamento eficaz dos objetivos e metas, integração entre os sistemas, base de dados para suporte ao planejamento e autoavaliação (ARAÚJO, 1996; MAGALHÃES, 2009; FALQUETO, 2012; SILVEIRA et al., 2009; VIDIGAL, CAMPOS, 2015).

Um Sistema de Informação preciso, com informações relevantes, é indispensável e se apresenta como base para o desenvolvimento organizacional, sendo, portanto, fundamental para o planejamento por ser uma fonte de consulta que permite conhecer e analisar fatores internos e externos que poderão impactá-lo e auxiliar a superar dificuldades de operacionalização (FANTAUZZI, 2009).

A necessidade da existência de profissionais com Know-how para trabalhar com o Planejamento Estratégico foi o segundo elemento mais enfatizado na literatura abordada. Termo inglês comumente utilizado no ambiente da administração, o know-how, refere-se à existência de pessoas qualificadas com os conhecimentos, habilidades e atitudes necessárias para o desenvolvimento de determinada atividade.

\section{POLÊM!CA $\mid$ LABORE}


Sem a devida capacitação dos envolvidos no processo de elaboração e implementação do PE, o processo está fadado ao fracasso. Enfrentará barreiras, tais como, ausência de ligação entre as atividades realizadas e os objetivos estratégicos, e a falta de conhecimento acerca do que seria necessário para implantar o plano (ESTRADA, 2000; FALQUETO, 2012; PETRASSI et al., 2013; VIDIGAL, CAMPOS, 2015).

O Acompanhamento e Avaliação também foi muito destacado pela literatura analisada. A avaliação faz parte do processo de planejamento e a ausência de sistemas consistentes de acompanhamento e avaliação, assim como indicadores que permitam determinar a eficiência, a eficácia, o impacto e a sustentabilidade dos programas, podem ser considerados problemas enfrentados durante a implementação das estratégias (PETRASSI et al., 2013; COSTA, 2014). A promoção de uma avaliação periódica, com base no acompanhamento e controle das ações de modo a atingir, eficaz e eficientemente, os objetivos traçados, corrigir ou modificar os novos rumos da instituição é fundamental para que estas melhorem seus resultados (ESTRADA, 2001).

Outro aspecto muito observado é o da Cultura Organizacional, pois tem relação direta com o sucesso ou fracasso de um modelo de PE. Compreender o comportamento organizacional ajuda os planejadores na formação da base de entendimento de atitudes, motivação e percepções de crenças, hábitos, ritos e valores de determinados grupos sociais, que devem ser levados em conta para poder aplicar com êxito a técnica administrativa (ESTRADA, 2000; MAGALHÃES, 2009; PICCHIAI, 2010).

O quinto elemento mais destacado é a Participação no Planejamento Estratégico, pois ele não apenas traz inúmeras vantagens e o enriquece, como também é considerado por muitos autores como fundamental para sua implementação. A participação, além de democrática, traz também vantagens gerenciais para o desenvolvimento do processo. Dentre essas vantagens, cabe destacar o aumento da legitimidade do plano frente à comunidade e aqueles que serão responsáveis pela sua implementação, proporcionando maior estímulo para o seu comprometimento com o sucesso do empreendimento (SANTOS et al., 2009; ATHANÁZIO, 2010).

A necessidade de considerar a Natureza da Organização é algo intrínseco ao planejamento estratégico em qualquer ambiente, mas, nas IFES, esse é reconhecidamente um fator relevante (ARAÚJO, 1996; BORGES e ARAÚJO, 2001; ATHANÁZIO, 2010; COSTA,

\section{POLÊM!CA $\mid$ LABORE}


2014). "Parece necessário compreender que as universidades são organizações com características próprias e específicas, o que requer uma forma diferenciada de gestão" (FALQUETO, 2012, p. 29).

Outro elemento crítico para o PE em IFES é a Estrutura Organizacional, pois afeta a forma como as partes da organização se relacionam, a maneira como o planejamento será elaborado e implementado, bem como sua aceitação pelos membros que a compõem. A falta de uma estrutura que facilite a implementação e a complexidade da organização universitária têm sido apontadas como elementos que influenciam o planejamento estratégico dessas instituições (ESTRADA, 2000, FALQUETO, 2012), sendo portanto, necessária sua adequação para atuação sinérgica e sincrônica de seus órgãos (PICCHIAI, 2010).

O oitavo elemento considerado mais relevante alude a Questões Políticas relacionadas ao poder político para influenciar a elaboração e/ou implementação do planejamento estratégico; as relações dos diversos grupos, cada qual com seus interesses, aspirações, valores, expectativas e crenças que determinam como se dará o processo; e, por fim, os próprios relacionamentos de poder entre os grupos que compõem a comunidade acadêmica.

O próximo elemento apontado pela literatura é a Presença da Liderança, que pode ser equiparada à importância das questões políticas, uma vez que determina diretamente o quanto de interesse há no sucesso desse empreendimento. O envolvimento direto de líderes da organização é fundamental para que o processo de planejamento possa se consolidar, pois sua presença pode facilitar o processo, assim como a ausência pode dificultá-lo (ESTRADA, 2000; FALQUETO, 2012; COSTA, 2014).

Por fim, o décimo elemento crítico mais abordado nas publicações analisadas foi a Adoção do PE como instrumento de gestão, ou seja, utilizar os objetivos, estratégias, ações e planos de trabalho, estabelecidos no PE, como guia das atitudes e ações da instituição. Estrada (2000) reconheceu a importância desse elemento ao recomendar a uma IFES que adotasse esse comportamento.

Parece redundante e desnecessário realçar a importância da adoção do PE como instrumento de gestão, pois se não for para utilizá-lo como tal, qual sentido possuiria a existência desse elemento nas organizações? Entretanto, estudos vêm retratando o PE desenvolvido nas IES apenas como um instrumento formal, fruto da burocracia interna e da

\section{POLÊM!CA $\mid$ LABORE}


exigência desse para credenciamento junto ao MEC - Ministério da Educação (FALQUETO, 2012; COSTA, 2014; SANTOS et al., 2009).

A adoção do PE como instrumento de gestão é o motor propulsor que demonstra a necessidade de aperfeiçoamento contínuo do processo de planejamento e execução. A partir do momento que esse elemento crítico é atendido, é que se percebe a necessidade da existência dos demais, como forma de fazer que a instituição torne viável sua aplicação.

É indispensável a adoção do PE como instrumento de gestão, uma vez que tal adoção agrega maior credibilidade ao processo e incentiva a melhoria contínua, por meio da repetição dos ciclos e reflexão necessária para sua elaboração e implementação. Quando o PE é adotado como instrumento de gestão, desde a sua elaboração até a implementação e avaliação, a organização cresce significativamente, pois a cada ciclo é exigida uma reflexão acerca do processo anterior e são avaliados os pontos que impulsionam ou retraem o desenvolvimento organizacional, multiplicando o conhecimento organizacional e proporcionando o aperfeiçoamento do processo e de todos os envolvidos na sua implementação.

\section{Conclusão}

O presente artigo buscou apresentar uma proposta de análise do PE no âmbito das IFES a partir de elementos críticos para sua integração com as ações realizadas.

Apesar de considerar a legitimidade e necessidade de atender às exigências legais que permeiam o desenvolvimento do Plano de Desenvolvimento Institucional - PDI, o foco do trabalho não é analisar o planejamento sob essa ótica, mas contribuir para aperfeiçoar o PE desse tipo de instituição sob a perspectiva gerencial, estimulando sua adoção como instrumento de gestão.

A utilização da pesquisa bibliográfica, com o auxílio da análise de conteúdo, permitiu identificar a existência de elementos destacados na literatura a ponto de serem considerados fundamentais para a gestão do planejamento estratégico no âmbito dessas instituições.

Os resultados permitiram apontar os dez principais elementos críticos para esse processo: Sistema de Informação; Know-how para trabalhar com o Planejamento Estratégico; Acompanhamento e avaliação; Cultura organizacional; Participação no Planejamento Estratégico; Natureza da organização; Estrutura organizacional; Questões políticas; Presença da liderança; Adoção do PE como instrumento de gestão.

\section{POLÊM!CA $\mid$ LABORE}


Ao mesmo tempo em que o PDI é um instrumento de cumprimento das exigências para credenciamento dos cursos superiores no MEC, também é considerado um instrumento de Planejamento Estratégico. Todavia, a literatura aponta que, em muitos casos, as preocupações acerca do PDI circundam o cumprimento de uma função meramente formal e burocrática.

Dessa forma, foi possível constatar a reiterada menção dos elementos críticos na literatura, uma vez que surge a necessidade de considerá-los para superar essa dificuldade e realçar o aspecto efetivamente gerencial do PDI, potencializando sua dimensão estratégica e utilizando-o como guia das ações da instituição.

Tais elementos apresentam uma outra perspectiva, ao fornecer subsídios para que os gestores de IES possam alternar o foco principal sob o qual têm observado o PDI, viabilizando sua consolidação como instrumento de gestão concomitantemente com o cumprimento das exigências formais.

\section{Referências}

ALBANO, C. S.; GARCIA, F. T. O Impacto do Método e de Fatores Organizacionais no Processo de Planejamento Estratégico: estudo de caso em uma universidade federal. Parc. Estrat, Ed. Esp., Brasília-DF, v. 18, n. 37, p. 151-172, jul./dez., 2013.

ANDREAZZA, M. da S. Competências: análise a partir do planejamento estratégico de um departamento de uma universidade federal. 2013. 22f. Monografia (Especialização em Gestão Empresarial) - Universidade Federal do Rio Grande do Sul, Porto Alegre, 2013.

ARAÚJO, M. A. D. Planejamento Estratégico: um instrumental à disposição das universidades?. Revista de Administração Pública, Rio de Janeiro, v. 30, n. 4, p. 74-86, 1996.

ATHANÁZiO, M. M. Processo de Planejamento Estratégico em Universidade Pública: o caso da Universidade Federal do Pará. 2010. 154 f. Dissertação (Mestrado em Políticas e Gestão Públicas; Gestão Organizacional) - Universidade Federal do Rio Grande do Norte, Natal, 2010.

BAENA, S. C. P. O Alinhamento do Plano Estratégico e Plano de Desenvolvimento Institucional (PDI) em uma Organização Universitária: possibilidades e limitações. 2012. 169f. Dissertação (Mestrado em Administração) - Programa de Pós-Graduação em Administração da Universidade Católica do Paraná, Curitiba, 2012.

BARDIN, Laurence. Análise de Conteúdo. Tradução de Luís Antero Reto, Augusto Pinheiro. São Paulo: Edições 70, 2011.

BOLZAN, C. I. M.; LORENTZ, M. H. N.; MADRUGA, L. R. R. G. Análise da Evolução do Plano de Desenvolvimento Institucional na UFSM. Revista de Ciências Sociais em Perspectiva, v. 11, n. 21, 2012, ISSN $1981-4747$

\section{POLÊM!CA $\mid$ LABORE}

Polêmica - Revista Eletrônica da Uerj - Rua São Francisco Xavier, 524, $1^{\circ}$ andar

bloco D, sl.1001 • Tels.: +55 21 2334-4088 / 4087 • http://www.e-publicacoes.uerj.br/index.php/polemica/index http://www.labore.uerj.br • laboreuerj@yahoo.com.br 
BORGES, D. F.; ARAÚJO, M. A. D. Uma Experiência de Planejamento Estratégico em Universidade: o caso do Centro de Ciências Sociais Aplicadas da UFRN. RAP, Rio de Janeiro, v. 35, n. 4, p. 63-76, 2001.

BRYSON, J. M. A Strategic planning for public and non-profit organizations. Pergamon Journals Ltd, Great Britain, v. 21, n. 1, p. 73-81, 1988.

CAMARA, R. R. Análise de Conteúdo: da teoria à prática em pesquisas sociais aplicadas às organizações. Gerais: Revista Interinstitucional de Psicologia, Juiz de Fora, v. 6, n. 2, p. 179-191, 2013.

CARDOSO, C. I. X. S. et al. O Planejamento Estratégico como Instrumento de Mudança na Universidade Federal de Pernambuco. In: XV Colóquio Internacional de Gestão Universitária - CIGU, Mar del Plata, Argentina, 2015. ISBN 978-85-68618-01-1.

COSTA, V. L. Análise da Implementação do Planejamento Estratégico em Universidades Públicas Federais: o caso da Universidade Federal do PAMPA. 2014. 215f. Dissertação (Mestrado em Gestão de Organizações Públicas) - Programa de Pós-Graduação em Administração da Universidade Federal de Santa Maria - UFSM, Santa Maria, 2014.

ESTRADA, R. J. S. Os Rumos do Planejamento Estratégico na Universidade Pública: um estudo de caso na Universidade Federal de Santa Maria. 2000. 206f. Tese (Doutorado em Engenharia de Produção) - Programa de Pós-Graduação em Engenharia da Produção da Universidade Federal de Santa Catarina, Florianópolis, 2000.

Os Rumos do Planejamento Estratégico nas Instituições Públicas de Ensino Superior. In: XXII ENEGEP, Salvador - BA, 2001.

FALQUETO, J. M. Z. A Implantação do Planejamento Estratégico em Universidades: o caso da Universidade de Brasília. 2012. 192f. Dissertação (Mestrado em Profissional em Administração) - Faculdade de Economia, Administração e Contabilidade da Universidade de Brasília, Brasília, 2012.

FANTAUZZI, O. A. Sistema de Planejamento Institucional da Universidade de Brasília: uma análise no plano anual de atividades. 2009. 42f. Monografia (Especialização em Gestão Universitária) - Universidade de Brasília, Brasília, 2009.

FORPLAD - Fórum Nacional de Pró-Reitores de Planejamento e Administração. Comissão de Planejamento. Planejamento Estratégico em Instituições Federais de Ensino Superior: proposta de processo participativo. Brasília, 1995.

GIACOBBO, Mauro. O Desafio da Implantação do Planejamento Estratégico nas Organizações Públicas. Revista do Tribunal de Contas da União, v. 28, n. 74, p. 73-105, Brasília, 1997.

HARGER, A. C. Planejamento Estratégico em Organização Universitária: um estudo de caso na Universidade Federal de Santa Catarina. 2011. 229f. Dissertação (Mestrado em Administração) - Universidade Federal de Santa Catarina, Florianópolis, 2011.

KOBUS, Mário. Avaliação da Gestão do Planejamento da Universidade Federal de Santa Catarina, Utilizando a Metodologia Multicritérios de Apoio à Decisão - MCDA. 2012. 197f. Dissertação (Mestrado em Administração Universitária) - Universidade Federal de Santa Catarina, Florianópolis, 2012.

MAGAlHÃES, A. C. Os Rumos do Planejamento Estratégico nos Centros Federais de Educação Tecnológica: um estudo de caso no CEFET-MG. 2009.133f. Dissertação (Mestrado em Educação) Universidade de Brasília, Brasília, 2009.

MARCONI, M. A.; LAKATOS, E. M. Fundamentos de Metodologia Científica. 7. ed. São Paulo: Atlas, 2010.

MÜLLER, C. J. Modelo de Gestão Integrado Planejamento Estratégico, Sistemas de Avaliação de Desempenho e Gerenciamento de Processos (Meio - Modelo de Estratégia, Indicadores e Operações). 2003.

\section{POLÊM!CA | LABORE (}

Polêmica - Revista Eletrônica da Uerj - Rua São Francisco Xavier, 524, $1^{\circ}$ andar

bloco D, sl.1001 • Tels.: +55 21 2334-4088/4087 • http://www.e-publicacoes.uerj.br/index.php/polemica/index http://www.labore.uerj.br • laboreuerj@yahoo.com.br 
292f. Tese (Doutorado em Engenharia de Produção) - Universidade Federal do Rio Grande do Sul, Porto Alegre, 2003.

OLIVEIRA, D. P. R. Planejamento Estratégico: Conceito, metodologia e práticas. 32ª ed. São Paulo: Atlas, 2014.

PALUDO, A. C.; PROCOPIUCK, M. Planejamento Governamental: referencial teórico, conceitual e prático. 2. ed. São Paulo: Atlas, 2014.

PEREIRA, J. F. A Modernização Administrativa das Instituições Públicas Federais - A administração estratégica como um novo enfoque gerencial para o IBGE. 1998. 127f. Dissertação (Mestrado em Administração Pública) - Escola Brasileira de Administração Pública, Rio de Janeiro, 1998.

PETRASSI, A. C. A.; BELLEN, H. M. V.; ALBERTON, L. Do Planejamento à Avaliação: uma análise do processo de implementação da gestão estratégica em uma instituição federal de ensino superior. In: XIII Colóquio Internacional sobre Gestão Universitária nas Américas, Buenos Aires, 2013.

PICCHIAI, D. Planejamento Estratégico Aplicado à Gestão de Universidade Pública. São Paulo: GVPesquisa, 2010.

As Metas e os Indicadores no Processo de Planejamento: o caso de uma universidade pública. In: XXXII Encontro Nacional de Engenharia de Produção. Bento Gonçalves, 2012.

Planejamento Estratégico e seus Instrumentos Aplicados em uma Universidade Pública. Ciências Sociais Aplicadas em Revista - UNIOESTE/MCR, v. 13, n. 25, p.223-233, 2013. ISSN 1679-348X.

REBELO, L. M. B.; ERDMANN, R. H.; COELHO, C. S. R. Contribuições da Teoria da Complexidade ao Processo de Planejamento Estratégico em Universidades. In: III Colóquio Internacional sobre Gestión Universitária en América del Sur, Buenos Aires, Argentina, 2003.

SANTOS, G. S. et al. Planejamento em IFES: a experiência da UFRB - Universidade Federal do Recôncavo da Bahia. In: XV Colóquio Internacional de Gestão Universitária - CIGU, Mar del Plata, Argentina, 2015, ISBN 978-85-68618-01-1.

SANTOS, J. L. S. et al. Modelo de Planejamento Estratégico em uma Universidade Pública Brasileira: desenvolvimento e implementação na Universidade Federal de Alagoas. In: IX Colóquio Internacional sobre Gestão Universitária da América do Sul, Florianópolis, 2009.

SILVA, H. A. et al. Análise de conteúdo: fazemos o que dizemos? Um levantamento de estudos que dizem adotar a técnica. In: IV Encontro de Ensino e Pesquisa em Administração e Contabilidade, Brasília, 2013.

SILVEIRA, E.W. et al. Uma Experiência de Planejamento Estratégico no Contexto da Universidade Federal de Goiás. In: IX Colóquio Internacional sobre Gestão Universitária da América do Sul, Florianópolis, 2009.

SILVEIRA, D. T. CORDOVA, F. P. A pesquisa Científica. In: GERHARDT, Tatiana Engel. SILVEIRA, Denise Tolfo. (Org.). Métodos de Pesquisa. Porto Alegre: Editora da UFRGS, 2009.

VIDIGAL, F.; CAMPOS, L. W. Do Planejamento Estratégico à Prática de Gestão na Universidade Pública: um estudo na UFG. In: XV Colóquio Internacional de Gestão Universitária -CIGU, Mar del Plata, Argentina, 2015, ISBN 978-85-68618-01-1.

Recebido em: 24/05/2017.

Aceito em: 30/07/2017.

\section{POLÊM!CA $\mid$ LABORE}

Polêmica - Revista Eletrônica da Uerj - Rua São Francisco Xavier, 524, $1^{\circ}$ andar

bloco D, sl.1001 • Tels.: +55 21 2334-4088/4087 • http://www.e-publicacoes.uerj.br/index.php/polemica/index

http://www.labore.uerj.br • laboreuerj@yahoo.com.br 